\begin{tabular}{l|l} 
American Journal of Dermatological Research and Reviews \\
(ISSN:2638-1893)
\end{tabular}

\title{
Oral Ivermectin should be considered as a Magic Therapy for
} Scabies with $98 \%$ Cure

\section{${ }^{1}$ Professor Khalifa E. Sharquie MD, PhD, FRCP Edin, ${ }^{2}$ Professor Adil A. Noaimi MD, DDV, FICMS, ${ }^{3}$ Dr. Riyam A. Flayyih MD.}

${ }^{1}$ Department of Dermatology, College of Medicine, University of Baghdad. Iraqi and Arab Board for Dermatology and Venereology, Baghdad Teaching Hospital, Medical City, Baghdad, Iraq. ${ }^{2}$ Department of Dermatology, College of Medicine, University of Baghdad. Iraqi and Arab Board for Dermatology and Venereology, Baghdad Teaching Hospital, Medical City, Baghdad, Iraq. ${ }^{3}$ Center of Dermatology; Baghdad Teaching Hospital; Medical City, Baghdad, Iraq.

\section{ABSTRACT}

Background: Scabies is one of the commonest endemic pruritic diseases all over the worldwide. Many topical therapeutic options for scabies are available, but none of them could be accepted by many patients as all of them need covering the whole body by ointment overnight. Accordingly patients are looking for safe oral therapy like many other diseases. Objective: To assess the effectiveness of oral ivermectin in the treatment of scabies. Patients and Methods: This single, blinded, therapeutic work was conducted in the Center of Dermatology and Venereology, Baghdad Teaching Hospital, Baghdad, Iraq during the period from April 2018 through October 2019. Fifty of patients with scabies were involved in this study. All socio-demographic data that related to the disease were obtained from each patient. History and clinical examination was done for each case to establish the diagnosis. Fifty patients treated by ivermectin tablet 200 microgram per $\mathrm{kg}$ as a single dose on empty stomach and repeated after one week. The patients were seen regularly every 2 weeks for 4 weeks duration after stopping therapy, to re-asses cure and to report any local or systemic side effects. Results: A total of 50 patients were included in this study, 21 (42\%) males and 29 (58\%) females. The ages of males ranged from 5-47 with a mean $20.90 \pm 13.034$ years; while the age range of females ranged from 3-67 (30.69 \pm 18.766$)$ years. At the end of four weeks after stopping therapy, the response to treatment was as follows: Response in $49(98 \%)$ patients and no response in $1(2 \%)$ patients. No cutaneous or systemic side effects were noticed in any patients, while the recurrence or relapse rate was documented in 2 (4\%) patients. Conclusion: Oral ivermectin had achieved cure of scabies in $98 \%$ of patients, hence it should be considered as a mass treatment in cases of outbreak and epidemics as it is easy to be used with no significant side effects especially when compared with topical agents.

Keywords: Oral Ivermectin, Therapy, Scabies.

*Correspondence to Author:

Dr. Riyam A. Flayyih MD.

Center of Dermatology; Baghdad Teaching Hospital; Medical City, Baghdad, Iraq.

How to cite this article:

Khalifa E. Sharquie, Adil A. Noaimi ,Riyam A. Flayyih. Oral Ivermectin should be considered as a Magic Therapy for Scabies with $98 \%$ Cure American Journal of Dermatological Research and Reviews, 2020, $x: x x$

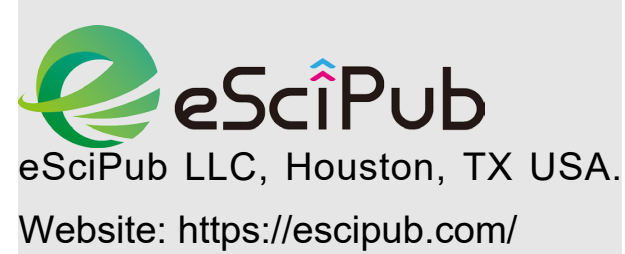

Website: https://escipub.com/ 


\section{Introduction}

Scabies has been a source of human infestation for more than 2500 years, dating back to Roman time (1). The infection is endemic in many impoverished communities, but prevalence rates vary widely; seasonal outbreaks and documented peaks during times of war are probably related to crowding and population movements. ${ }^{(2)}$ In some industrialized countries, scabies is endemic in economically disadvantaged populations, and outbreaks occur in nursing homes and hospitals. ${ }^{(3)}$ In Iraq scabies is endemic since early 1980 and outbreak and even epidemic might run from time to time and this related to times of wars and economic blockade. It tends to affect younger age groups ( $0-5$ years), and to lesser extent in older age patients. There was male predominance male: female ratio was 2:1 and about half of the patients were married ${ }^{(4)}$.

Many topical modalities of therapy that has been used in treatment of scabies like gammabenzene-hexachloride (Lindane 1\%), benzyl Benzoate $25 \%$, crotamiton $10 \%$, \%, permethrin $5 \%$, malathion liquid $(0.5 \%)$, thiabendazole and ivermectin cream $1 \%$,but unfortunately all of them were used topically and no one of them showed a high cure rate for this disease, In addition to that all of them differ in mechanism of action, duration of application, cost effectiveness, associated with side effects, relapse and recurrence rate ${ }^{(5)}$.

Ivermectin is a macrocyclic lactone produced by Streptomyces avermitilis. Although not FDAapproved for scabies, ivermectin represents an effective treatment for this and other ectoparasitic infestations. $(6,7)$ It acts by blocking transmission across nerve synapses that utilize glutamate ory-aminobutyric acid (GABA), hence causes paralysis of peripheral motor function in insects and acarines. (6, ${ }^{7)}$ Although GABA and glutamate are neurotransmitters within the human cerebral cortex, after early infancy, the blood-brain barrier prevents CNS penetration of the drug. Ivermectin is not recommended for children who weigh <33pounds $(15 \mathrm{~kg})$, pregnant women (category C), or breast feeding mothers. (8) Ivermectin is contraindicated in patients with an allergy to ivermectin and CNS disorders. In clinical studies, ivermectin has proven to be extremely safe as over 18 million people $>5$ years of age have been treated annually with ivermectin in the World Health Organization (WHO) Onchocerciasis Eradication Program. An increased death rate in elderly patients who received ivermectin in a single retrospective study ${ }^{(9)}$ was determined to be causally unrelated to the medication by the WHO, medical examiners, and the scientific community.

Oral ivermectin is easier to administer than traditional topical scabicides, thus facilitating treatment of large populations. A single dose of oral ivermectin 200 micrograms $/ \mathrm{kg}$ of body weight is effective. ${ }^{(10)}$ Ivermectin may not sterilize scabies eggs and a second dose given after one week has been shown to increase the response, ${ }^{(11)}$ and hence a second dose of ivermectin is recommended. ${ }^{(2,12)}$ Still the importance of this second dose for scabies control need to be further evaluated. ${ }^{(12)}$ Although there is only one report to date of clinical resistance to this agent by the scabies mite ${ }^{(13)}$, increased in vitro survival times of mites exposed to ivermectin have been described in communities with a high prevalence of scabies. ${ }^{(14)}$ Ivermectin is apparently a safe drug as no congenital abnormalities are reported with a low incidence of adverse effects such as headache, pruritus, pains in the joints and muscles, fever, maculo-papular rash, and lymphadenopathy, which were observed in patients with filariasis. Whether these symptoms are directly related to drug action or secondary to destruction of the filariae remains unclear. (15)In patients with sub-ungual disease, addition of a topical scabicide is recommended because a systemic medication will not penetrate into thickened keratotic debris. Also patients with crusted scabies who fail treatment despite appropriate environmental measures, consider both topical permethrin 5\% every 2-3 days for 1 
to 2 weeks and oral ivermectin (200 $\mathrm{mcg} / \mathrm{kg} / \mathrm{dose}$ ) administered as three doses (days 1,2 and 8) or as five doses (days 1, 2, 8, 9 , and 15), depending upon the severity of the infection. (2)

As many patients could not accept topical therapy as it needs covering the whole body by ointment over the nights. Accordingly patients are looking for oral therapy to be easy used like many other diseases.

So the aim of this work was to assess the effectiveness of oral ivermectin in the treatment of patients with scabies.

\section{Patients and Methods}

This is a single blind therapeutic study to evaluate the effectiveness of oral ivermectin in treatment of scabies. Fifty patients with scabies were included in this work which conducted in the Center of Dermatology and Venereology, Baghdad Teaching Hospital, Baghdad, Iraq during the period from April 2018 through October 2019. The diagnosis was established on clinical basis.

\section{Diagnosis based on:}

- Presence of itching ranging from mild, moderate to severe (wakeup at nights).

- Presence of characteristic pruritic papule, pustules and vesicles with or without excoriation.

- Presence of one burrow or more.

- Seeing mites, eggs and scybala under light microscope

- Presence of nodules.

\section{Exclusion criteria:}

- Patients without burrows.

- Recurrent attacks of scabies (for any reason).

- Patients with chronic disease (renal failure, malignancy, uncontrolled diabetes mellitus, immunocompromized and other chronic disorder....etc).

- Patients less than one year of age.

- Pregnant and lactating women.
- Allergy to Ivermectin.

- CNS disorders

Formal consent was taken from each contact persons after full explanation about the goal and nature of the present study. Also, ethical approval was given by the Scientific Council of Dermatology and Venereology-Arab Board for Medical Specializations.

Full history was taken from each case considering the following points: age, gender, occupation, residence, marital state, education, number of family members, duration of the disease, presence of itching and characterized by severe itching wakeup at night, history of previous treatment, positive family history of scabies, predisposing history like prison, travel, occupation, medical history (DM, other disease) and drug intake.

Careful physical examinations was carried out and scraping of burrows was done to be seen under light microscope looking mite, eggs or scybala.Also sites or distribution of burrows, characteristic pruritic papules, pustules, vesicles and nodules were assessed.Pre and post treatment photographs were taken using Samsung-digital, note5 high sensitivity, 16 mega pixels, camera, in the same place with fixed illumination and distance.

Fifty patients treated by ivermectin tablet 200 microgram per kg after 2 hours from dinner and repeated after one week. Ivermectin tablet as Avoctin $\AA$ tablet $6 \mathrm{mg}$ manufactured for Laboratory Innotech International Chouzy, made in France.

\section{Follow up and Assessment of drug effectiveness:}

The patients were seen regularly every two weeks for four weeks after stopping treatments. At each visit the response to treatment was assessed according to the change in itching severity especially wakeup at nights and disappearance of burrows, characteristic pruritic (papules, pustules, vesicles), excoriation and nodules disappearance or new nodules appearance. Any sign or symptom of systemic side effects of drug was also reported. 
Assessment of drug effectiveness and disease clearance was based on following.

- Response; disappearance of burrows, characteristic pruritic papules, pustules, vesicles and reduction of itching from severe to moderate, mild and nil, occurs in the 1st two weeks after stop treatments and much better in the next weeks.

- No response; in patients had one burrow or more, characteristic pruritic papules, pustules, vesicle and excoriation still present or not, itching ranging from mild to severe with much worse in the next weeks.

- Recurrence or relapse; occurs in patient presented with response after treatment then had one burrow or more with characteristic pruritic papules, pustules and vesicles, itching ranging from mild, moderate to severe (wakeup at night) and the patients had more sign and symptoms in the next weeks.

\section{Complication of disease and treatments:}

Skin infection like impetignization, fever and lymph node enlargement. Post-scabietic itching ,eczematous dermatitis, scabietic nodules .Also psychological complications and post- streptococcal glomerulonephritis should be watched.

Side effects of drugs include fever, headache, chills, arthralgia, rash, and anorexia.

Statistical analysis: Descriptive statistics (Measures of central tendencies and dispersion; like mean and standard deviation) were used together with analytic statistics (Chi-square) using EPI-Info version 20.

\section{Results}

A total of 50 patients were enrolled in this study, $21(42 \%)$ males and $29(58 \%)$ females, the age range of males was from 5-47 (20.90 \pm 13.034$)$ years while the age range of females was from 3-67 (30.69 \pm 18.766$)$ years. The disease duration ranged from 1 week to 16 weeks with a mean \pm SD of $5.98 \pm 3.455$ weeks. Itching was reported in 50 patients which varied in severity from $1(2 \%)$ mild, $2(4 \%)$ moderate and $47(94 \%)$ severe (wakeup at night) patients. Family history of scabies was found in $48(96 \%)$ patients. Burrows found in all 50 (100\%), characteristic pruritic (papules, pustules and vesicles) with or without excoriation were found in $50(100 \%)$ and nodules were noticeable in 39 (78\%) (Table-1).

Table-1: Demographic data of the patients at time of presentation before treatment.

\begin{tabular}{|c|c|c|c|}
\hline \multicolumn{3}{|c|}{ Sociodermographic information } & \multirow{2}{*}{$\begin{array}{l}\text { Group } \\
5-47\end{array}$} \\
\hline \multirow{4}{*}{ Age } & \multirow{2}{*}{ Range } & M & \\
\hline & & $\mathrm{F}$ & $3-67$ \\
\hline & \multirow{2}{*}{ mean $\pm S D$} & M & $20.90 \pm 13.034$ \\
\hline & & $\mathrm{F}$ & $30.69 \pm 18.766$ \\
\hline \multirow{2}{*}{ Gender } & \multicolumn{2}{|l|}{ Male No.\&\% } & $21(42.0 \%)$ \\
\hline & \multicolumn{2}{|l|}{ Female No.\&\% } & $29(58.0 \%)$ \\
\hline & \multicolumn{2}{|l|}{ Children } & 7 \\
\hline & \multicolumn{2}{|l|}{ Students } & 14 \\
\hline & \multicolumn{2}{|l|}{ Office work } & 2 \\
\hline & \multicolumn{2}{|l|}{ Military } & 5 \\
\hline & \multicolumn{2}{|l|}{ Private work } & 15 \\
\hline 离 & \multicolumn{2}{|l|}{ House wife } & 14 \\
\hline ठ̊. & \multicolumn{2}{|l|}{ Retired and old age } & 3 \\
\hline
\end{tabular}


The response to treatment after two weeks of stopping therapy:

Response was noted in $45(90 \%)$ patients with a reduction in severity of itching to moderate in $21(47 \%)$ patients and mild in $17(38 \%)$ patients and nil in $7(15 \%)$ patients. Also disappearance of burrows and characteristic pruritic (papules, pustules and vesicles) were observed in all these patients 45 (90\%). Regarding nodules were found in $15(34 \%)$ patients but not present in $30(66 \%)$ patients. Side effects were not documented in any patients (Table-2).

No response was noted in 5 patients and as follow: in a form of severe itching in 5 patients with burrows in 2 patients, while characteristic pruritic (papules, pustules and vesicles) were seen in all these 5 patients. While nodules were found in 3 patients. There was statistically significant Chi-square $\left(\chi^{2}\right)=22.97$ and $\mathrm{P}$-value $=0.0000016$. No side effects were reported in all patients.

Table-2: The response to treatment after two weeks of stopping therapy.

\begin{tabular}{|l|l|l|l|}
\hline \multirow{2}{*}{ Group } & \multicolumn{2}{|l|}{} \\
\cline { 3 - 4 } Response & Response & No. & $\%$ \\
\cline { 3 - 4 } & No response & 45 & 90 \\
\hline Total & & 5 & 10 \\
\hline P-value & 50 & 100 \\
\hline
\end{tabular}

Chi-square $\left(\chi^{2}\right)=22.97$ and $P$-value $=0.0000016$.

The response to treatment after 4 weeks of stopping therapy:

Response was noted in 49 (98\%) patients (Table-3) with a reduction in severity of itching to moderate in $9(18 \%)$ patients, mild in $15(30 \%)$ and nil in $35(52 \%)$ patients; disappearance of burrows and characteristic pruritic (papules, pustules and vesicles) were noted in $49(98 \%)$ of patients, while nodules were found in $9(18 \%)$ patients.
No response was noted in $1(2 \%)$ patient with severe itching, while characteristic pruritic (papules, pustules and vesicles), nodule were present but no burrow was seen.

Recurrence or relapse was documented in 2 (4\%) patients.

There was statistically significant Chi-square $\left(\chi^{2}\right)$ $=34.22$, P-value less than 0.00000001 .

Table-3: The response to treatment after 4 weeks of stopping therapy.

\begin{tabular}{|l|l|l|l|}
\hline \multirow{2}{*}{ Group } & Group \\
\cline { 3 - 4 } & Response & No. & $\%$ \\
\hline \multirow{2}{*}{ Response } & Non response & 49 & 98 \\
\hline Total & 1 & 2 \\
\hline$P$-value & 50 & 100 \\
\hline
\end{tabular}

Chi-square $\left(\chi^{2}\right)=34.22$, $\mathrm{P}$-value less than 0.00000001 . 


\section{Discussion}

Scabies is one of the commonest endemic diseases in the world, particularly in the developing world including Iraq (16). There are many therapeutic options that have been used in treatment of scabies ${ }^{(5)}$.

But none of these topical agents could be accepted by many patients as they need to be applied all over the body for nights. Also all these topical therapies are not suitable for outbreaks and epidemics of scabies.

Hence we urgently need oral drug to be easily used by all patients in a condition of mass treatment.

Recently systemic ivermectin has been introduced for treatment of scabies but still not FDA approved.

Although ivermectin has been tried in treatment of scabies through multiple studies and in different countries but to the best of our knowledge, this is the first study in Iraq has been done to assess and evaluate the effectiveness of oral Ivermectin in treatment of scabies,

As scabies is running an endemic disease. The results of present work showed that cure rate of oral Ivermectin in treatment of scabies was $90 \%$ at the end of second weeks and $98 \%$ at end of fourth weeks after stopping therapy which comparable with other literature that showed a cure rate of $70 \%-73 \%$ as a single dose of Ivermectin which increased to $95 \%-98 \%$ with 2 doses given at 2 week interval. ${ }^{(11,17)}$, No side effects was recorded in all patients using oral ivermectin in the present study which is unlike to what had been published which showed fever, headache, chills, arthralgia, rash, eosinophilia, and anorexia, otherwise no significant drug interactions have been reported. (14, 18). According to the systematic review and metaanalysis of randomized controlled trials which published on January 2018 in JAAD,showed side effects of oral ivermectin around 4.3\% $(26 / 604)^{(19)}$. The high cure rate of oral ivermectin could be attributed to its broad-spectrum antiparasitic agent ${ }^{(20,21)}$, Ivermectin contains $90 \%$ or more of ivermectin $\mathrm{B} 1 \mathrm{a}$ and less than $10 \%$ of ivermectin $\mathrm{B} 1 \mathrm{~b}$, so ivermectin $\mathrm{B} 1 \mathrm{a}$ is considered the main ingredient that elicits pharmacological effect (22). The Present work showed 2(4\%) recurrence or relapse rate after oral Ivermectin in comparison with $14 \%(122 / 860)$ in the published literature (19). Regarding the cost effectiveness, the present work showed that oral ivermectin was non costly compared with permethrin . (23).

Brooks et al. (24) compared single oral dose of ivermectin with topical benzyl benzoate for the treatment of pediatric scabies and demonstrated that ivermectin was better than benzyl benzoate for the treatment of pediatric scabies. Next study showed that a single dose of ivermectin was as effective as single applications of sulfur 10\% ointment at the 2-week follow-up. After repeating the treatment, ivermectin was superior to sulfur $10 \%$ ointment at the 4-week follow up. ${ }^{(25)}$ Sharquie et al (2012) evaluated the therapeutic regimen of $8 \%$ and $10 \%$ topical precipitated sulfur in petrolatum ointment for single day, three successive nights or three successive days at total 97 patients with scabies and they revealed that single-day application was much less effective than three-days treatment, as single day showed only $42.4 \%$ cure. While in group who received sulfur ointment for three successive nights, the response was $90.6 \%$ which is comparable with those who received the treatment for three successive days $(96.9 \%)$. However, patients who were received only single dose of sulfur ointment fewer side effects were observed (26). Another studies showed that oral ivermectin is less effective than topical permethrin, depending on systematic review and meta-analysis of randomized controlled trials which published on January 2018 in JAAD, after searching 461 potential articles and We ultimately included 15 randomized controlled trials ${ }^{(19)}$.

While in the most recent review, in the last twoyears published report online by The New England Journal of Medicine at July 2019: at the 24-months follow-up visit, 823 participants were enrolled in the three trial groups, including 641 
participants who had been evaluated at baseline and 182 newly enrolled participants and the results were as follow: the prevalence of scabies at 24 months was $3.6 \%$ in the ivermectin group, $13.5 \%$ in the permethrin group, and $15.2 \%$ in the standard-care group, while the prevalence of impetigo at 24 months was $2.6 \%$ in the ivermectin group, $8.9 \%$ in the permethrin group, and $13.0 \%$ in the standard-care group. So they concluded that the mass administration of an ivermectin-based regimen reduced the prevalence of scabies 24 months after the intervention, with an additional effect on impetigo reduction. (27).

Conclusion: The cure of scabies was $98 \%$ of treated patients, hence ivermectin should be considered as a magic therapy especially when compared with topical agents especially in situation of outbreaks and epidemics.

\section{References}

1. Currier RW, Walton SF, Currie BJ. Scabies in animals and humans: history, evolutionary perspectives, and modern clinical management. Annals of the New York Academy of Sciences. 2011 Aug; 1230(1):E50-60.

2. Currie BJ, McCarthy JS. Permethrin and ivermectin for scabies. New England Journal of Medicine. 2010 Feb 25; 362(8):717-25.

3. Scheinfeld N. Controlling scabies in institutional settings. American Journal of clinical dermatology. 2004 Feb 1; 5(1):31-7.

4. Al-Badri AA. Epidemiological and therapeutic study of scabies in Baghdad (Master thesis in Community Medicine, College of Medicine University of Baghdad), 1994

5. Scott GR, Chosidow O; IUSTI/WHO .European guideline for the management of scabies, 2010.Int J STD AIDS. 2011 Jun; 22(6):301-3.

6. Meinking T, Burkhart CG, Burkhart CG, James R. Ectoparasitic diseases in dermatology: reassessment of scabies and pediculosis, pp. 77-108. Advances in dermatology, vol. 15. 1999.

7. Meinking TL, Taplin D, Herminda JL, Pardo R, Kerdel FA. The treatment of scabies with ivermectin. New England Journal of Medicine. 1995 Jul 6; 333(1):26-30.

8. Workowski KA, Bolan GA. sexually transmitted diseases treatment guidelines, 2015. MMWR. Recommendations and reports: Morbidity and mortality weekly report. Recommendations and reports. 2015 Jun 5; 64(RR-03):1.

9. Barkwell R, Shields $S$. Deaths associated with ivermectin treatment of scabies. The Lancet. 1997; 349(9059):1144-5.

10. Marks M, Taotao-Wini B, Satorara L, Engelman D, Nasi T, Mabey DC, Steer AC. Long term control of scabies fifteen years after an intensive treatment programme. PLoS neglected tropical diseases. 2015 Dec;9(12).

11. Usha V, Nair TG. A comparative study of oral ivermectin and topical permethrin cream in the treatment of scabies. Journal of the American Academy of Dermatology. 2000 Feb 1;42(2):23640.

12. Strong $M$, Johnstone $P$. Interventions for treating scabies. Cochrane Database of Systematic Reviews. 2007(3).

13. Currie BJ, Harumal P, McKinnon M, Walton SF. First documentation of in vivo and in vitro ivermectin resistance in Sarcoptes scabiei. Clinical Infectious Diseases. 2004 Jul 1; 39(1):e8-12.

14. Mounsey KE, Holt DC, McCarthy JS, Currie BJ, Walton SF. Longitudinal evidence of increasing in vitro tolerance of scabies mites to ivermectin in scabies-endemic communities. Archives of dermatology. 2009 Jul 1; 145(7):840-1.

15. Roos TC, Roos S, Merk HF, Bickers DR. Pharmacotherapy of ectoparasitic infections. Drugs. $2001 \mathrm{Jul}$ 1; 61(8):1067-88.

16. Fuller LC. Epidemiology of scabies. Current opinion in infectious diseases. $2013 \mathrm{Apr}$ 1; 26(2):123-6.

17. Fawcett RS. Ivermectin use in scabies. American family physician. 2003 Sep 15; 68(6):1089-92.

18. Steer AC, Kearns T, Andrews RM, McCarthy JS, Carapetis JR, Currie BJ. Ivermectin worthy of further investigation. Bulletin of the World Health Organization. 2009;87:A-B.

19. Dhana A, Yen H, Okhovat JP, Cho E, Keum N, Khumalo NP. Ivermectin versus permethrin in the treatment of scabies: A systematic review and meta-analysis of randomized controlled trials.

20. Engelman D, Martin DL, Hay RJ, Chosidow O, McCarthy JS, Fuller LC, Steer AC. Opportunities to investigate the effects of ivermectin mass drug administration on scabies. Parasites \& vectors. 2013 Dec; 6(1):106.

21. Ichikawa $M$, Tanaka $M$, Naritomi $Y$, Furue $M$. Combined ivermectin and topical therapy significantly reduces treatment time in aged 
scabietic patients. The Journal of dermatology.

2013 Apr 5; 4(40):306-7.

22. Sasaki I. What kind of drug is ivermectin? In: Nanko $\mathrm{H}$, ed. Scabies Management Perfect Guide. Tokyo: Shujunsha, 2008; 124-13..

23. Mounsey KE, McCarthy JS. Treatment and control of scabies. Current opinion in infectious diseases. 2013 Apr 1; 26(2):133-9.

24. Brooks PA, Grace RF. Ivermectin is better than benzyl benzoate for childhood scabies in developing countries. Journal of paediatrics and child health. 2002 Aug; 38(4):401-4.

25. Alipour $H$, Goldust $M$. The efficacy of oral ivermectin vs. sulfur $10 \%$ ointment for the treatment of scabies. Annals of parasitology. 2015;61(2):79-84.

26. Sharquie KE, Al-Rawi JR, Noaimi AA, Al-Hassany $\mathrm{HM}$. Treatment of scabies using $8 \%$ and $10 \%$ topical sulfur ointment in different regimens of application. Journal of drugs in dermatology: JDD. 2012 Mar; 11(3):357-64.

27. Romani L, Whitfeld MJ, Koroivueta J, Kama M, Wand H, Tikoduadua L, Tuicakau M, Koroi A, Andrews RM, Kaldor JM, Steer AC. Mass drug administration for scabies-2 years of follow-up. New England Journal of Medicine. 2019 Jul 11; 381(2):186-7. 